\title{
Movimentos sociais e experiência geracional: a vivência da infância no Movimento dos Trabalhadores sem Terra
}

\author{
Social movements and generation experience: \\ childhood lived within the Movimento dos Sem Terra/Brazil \\ Luciana Oliveira Correia ${ }^{1}$ \\ Maria Amélia Gomes Castro Giovanetti ${ }^{2}$ \\ Maria Cristina Soares Gouvêa ${ }^{3}$
}

\section{RESUMO}

O trabalho apresenta pesquisa etnográfica desenvolvida com crianças moradoras de um acampamento do Movimento dos Sem Terra, em Minas Gerais. Pela observação participante do cotidiano infantil e por meio de entrevistas com crianças, buscou-se apreender os significados da vivência da infância no interior de um movimento social organizado. No escopo deste artigo, no diálogo com os refereciais teórico-metodológicos da sociologia da infância, foram analisadas três das entrevistas realizadas, de forma a destacar a singularidade dos processos socializatórios vividos por tais sujeitos, definidos por duas categorias identitárias: geração e inserção em movimentos sociais. Verifica-se que as crianças, em sua ação coletiva voltada para a atividade do brincar, buscavam interpretar sua experiência coletiva, lançando mão de elementos da cultura infantil, de forma a elaborar o vivido. Ao mesmo tempo, buscavam estabelecer relações com outros universos sociais, tais como a escola, de maneira a construir novos espaços de sociabilidade.

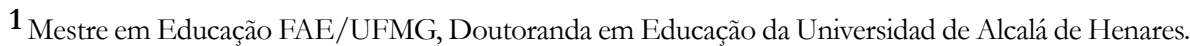

2 Professora da Faculdade de Educação da UFMG/Pesquisadora do Núcleo de Educação de Jovens e Adultos - Pesquisa e Formação (NEJA). ameliagcg@terra.com.br.

3 Professora da Faculdade de Educação da UFMG, Pesquisadora do Grupo de Estudos e Pesquisas em História da Educação da UFMG (GEPHE). crisoares@yahoo.com.br.
} 
Palavras-Chave: Infância; Movimento Social; Identidade; Socialização.

\begin{abstract}
This papper describes an etnographical research realized with a group of childs from the Movimento dos Sem Terra of Minas Gerais/Brazil. Using metodologies strategies like participative observation and interviews, we focused the signification of childhood experience inside an organized social movement. According to that, in dialogue with the teorical references of Childhood Sociology, the research analises their identity construction process, considering two central categories: generation and insertion in social movements. The children, in coletive action centered on playing, uses it to interpret their social universe, elaborating their own experience. In other hand, they tried to construct new relations with another social universes, like school, in order to increase their sociabilities.
\end{abstract}

Keywords: Childhood, social movement, identity; socialization.

\title{
INTRODUÇÃO
}

A recente produção sociológica brasileira voltada para a análise dos movimentos sociais contemporâneos tem tido como foco privilegiado o estudo do papel de novos atores, protagonistas de tais movimentos, com suas inscrições identitárias múltiplas, definidoras de novas estratégias de ação social. Nessa perspectiva, vêm sendo alargadas as categorias sociológicas de apreensão dos sujeitos, desde a ressignificação do conceito de classe até a incorporação de outras categorias informadoras de construção de identidades sociais, tais como gênero, raça, religião, trabalhadas de maneira entrecruzada. Mais recentemente, uma série de investigações tem contemplado o estudo do protagonismo juvenil na cena contemporânea e, com isso, conferido centralidade à categoria geração, na análise dos processos identitários. 
Tais trabalhos buscam superar uma análise dos processos de formação humana advinda das teorias psicológicas que produziu uma visão essencialista, conformadora de um modelo universal e normativo do desenvolvimento do indivíduo, fazendo emergir a diversidade de significados da experiência geracional nas sociedades contemporâneas. Nos estudos sociológicos brasileiros, porém, a categoria geração ainda tem privilegiado pouco outros recortes etários, com desenvolvimento de investigações sobre as diversas experiências da infância e da velhice.

Destaca-se, no entanto, uma produção crescente fundada no diálogo com o referencial teórico-metodológico da sociologia da infância, que tem informado significativa parte dos estudos sobre a criança brasileira. Observa-se a constituição de grupos interdisciplinares de pesquisa sobre a infância, que, a partir da produção de dissertações, teses e investigações nos programas de pós-graduação, têm desenvolvido estudos sobre a criança na relação com os diversos espaços sociais de inserção ${ }^{4}$. Porém, como afirma Quinteiro (2002): “ainda está por fazer-se a sociologia da infância no Brasil"”.

A chamada sociologia da infância centra-se na investigação dos processos de inserção e participação da criança na cena social contemporânea. Busca-se apreender o impacto e as consequências dos recentes processos históricos de globalização sobre as crianças, em distintos contextos, considerando o grau de vulnerabilidade delas em relação aos mecanismos de exclusão social (SARMENTO, 2004). Entre

\footnotetext{
4 Cabe destacar as seguintes publicações, nos últimos anos: GHIRALDELI, P. (Org.). Infância, escola e modernidade. Curitiba: UFPR, 1997; KRAMER, S.; LEITE, M. I. (Org.). Infância: fios e desafios da pesquisa. Campinas: Papirus, 1997; KRAMER; SOUZA (Org.). Infância e produção cultural. Campinas: Papirus, 1998; FARIA, A. L.; DEMARTINI, Z.; PRADO, P. (Org.). Por uma cultura da infância. Campinas: Autores Associados, 2002; SOUZA, S. (Org.). Educação @ pósmodernidade. Rio de Janeiro: 7letras, 2003; SILVA, A.; MACEDO, A. V.; NUNES. A. (Org.). Crianças indígenas: ensaios antropológicos. São Paulo: Global, 2002; DELGADO \& MULLER (Org.). Dossiê Sociologia da Infância: pesquisas com crianças.
} 
outros fatores, a padronização de modelos identitários infantis, presentes nos bens de consumo da cultura massificada, confronta-se com a desigualdade no acesso a tais produtos, definindo-se novas formas de exclusão.

Por outro lado, subjaz ao campo a perspectiva de compreensão da criança como ator social que, pela recepção de produções adultas e pela construção de práticas culturais singulares, dá significado à experiência social, definida por sua identidade geracional.

Cabe interrogar sobre o significado e as implicações de tomar a criança como ator social ${ }^{5}$. Tal definição indica um diálogo com as teorias sociológicas que conferem ao sujeito um protagonismo na configuração das dinâmicas sociais. Preconiza-se, por um lado, uma escala investigativa microanalítica, fundada no estudo das interações sociais entre os atores. Por outro, toma-se como foco os processos pelos quais eles afirmam suas identidades, por meio de práticas culturais voltadas para a interpretação de seu lugar social.

Assim é que os estudos contemporâneos sobre a infância buscam superar uma visão "menorizadora" da experiência infantil, considerando que as crianças constroem formas próprias de significar o mundo, a partir da singularidade, historicamente construída, do seu lugar social. Busca-se apreender tanto as estratégias e os processos infantis de interpretação do mundo, quanto as produções culturais deles decorrentes.

Nessa direção, o conceito de socialização tem papel central nos estudos sociológicos sobre a infância. Os processos socializatórios assumem sentido dinâmico, superando uma perspectiva sociológica

\footnotetext{
5 Para o aprofundamento desta questão, vide SARMENTO, Manuel. Gerações e alteridade: interrogações a partir da sociologia da infância. In: Dossiê Sociologia da Infância: pesquisas com crianças. Educação e Sociedade. Rio de Janeiro, n. 81 v. 26, p. 361-378, maio/ago. 2005. SIROTA, Regine. Emergências de uma sociologia da infância: evolução do objeto e do olhar. In: Cadernos de Pesquisa. São Paulo, n. 112, p 7-31, mar. 2001.
} 
funcionalista que apreende a socialização apenas como a entrada das novas gerações numa ordem instituída. Ao contrário, ao entender as crianças como atores sociais, a experiência socializatória assume sentido diverso, destacando-se, no dizer de Pinto (1998, p. 66): “os modos diferenciados como as crianças usam, se apropriam e atribuem sentido aos espaços, tempos, serviços e lógicas das instituições criadas pela sociedade adulta para a socialização dos mais pequenos".

Nesse processo de inserção na ordem social, as crianças revelam uma produção cultural diferenciada, resultante da interação com o mundo adulto, formulando o que se define como cultura infantil. Nos trabalhos da sociologia da infância, o estudo da cultura infantil é central, indicando um enfoque interdisciplinar, no diálogo com a teoria antropológica e com os chamados estudos culturais.

Tem-se como objeto de análise privilegiado o estudo das manifestações e dos significados da cultura infantil. Entende-se que a criança interpreta o mundo, dialogando com os elementos da cultura mais ampla, apropriando-se deles com base em uma lógica própria - a infantil. Lógica que é produto não da natureza biológica diferenciada, abstrata e universal, mas de longo processo histórico de conformação de um lugar social distinto do adulto. Nesse processo, foi sendo construída uma cultura singular no interior da e em relação com a cultura adulta ${ }^{6}$.

Ao tomar a criança como ator social, a sociologia da infância busca contemplar as produções que expressam a especificidade contemporânea do olhar infantil. Nessa direção, investigam-se as estratégias e os processos de transmissão da cultura infantil, analisando as

\footnotetext{
6 Outro significado para a expressão "cultura infantil" refere-se ao estudo das produções culturais do adulto dirigidas à criança, inventariando e analisando o vasto repertório constituído de literatura, jogos, brincadeiras, músicas, histórias, teatro, cinema, artes plásticas, formulado como estratégia de socialização dos mais jovens, configurando uma cultura material e simbólica distinta. Em tal produção, a criança emerge como sujeito do consumo, inserida na cultura de massa, em que a lógica mercadológica superpõe-se, grande parte das vezes, à dimensão cultural.
} 
experiências da vivência da infância e as ações sociais das crianças na cena contemporânea, bem como as produções decorrentes, tais como desenhos, músicas, brincadeiras, etc.

O estudo da cultura infantil tem conferido centralidade à análise do brincar, atividade por meio da qual o patrimônio cultural é transmitido por gerações e apropriado pelos sujeitos infantis. Patrimônio esse que tem como característica ser adquirido por meio da imersão na ação do brincar. É por intermédio de sua reprodução, na brincadeira, que tal repertório se mantém, atravessando séculos.

Nas pesquisas sobre o brincar, tem-se privilegiado a apreensão do significado disso. No brincar, a criança se interroga sobre o mundo no qual ela se situa e o estranha (estranhamento que é a condição primeira para a compreensão e a construção do conhecimento). Por meio da brincadeira, a criança desnaturaliza o mundo social ao trabalhar sua estereotipia. A criança não reproduz, em sua brincadeira, o mundo tal como ela o vive, mas recria-o, explorando os limites de sua construção. Como linguagem, o brinquedo traz em si uma gramática própria, que não constitui a reprodução do real. A criança não pensa o mundo para expressá-lo na brincadeira, mas o significa por meio do brincar. Assim é que a brincadeira transcende o real, elabora as múltiplas possibilidades de sua construção.

O caráter lúdico media a ação da criança no mundo. Em suas atividades, a criança constrói um sentido que não está na objetividade dos resultados buscados pelo adulto, mas no prazer da sua execução. Prazer que vem de brincar com os objetos, os seres e a linguagem, emprestando-lhes um sentido que vai além da realidade imediata. No dizer de Souza (1997, p. 31):

A criança está pronta para criar outros sentidos para os objetos que possuem significados fixados pela cultura dominante, ultrapassando o sentido único que as coisas novas tendem a adquirir. Tal atividade de brincar dá-se no diálogo com o mundo 
adulto. A criança não apenas transgride através de sua ação lúdica o real, mas tenta compreendê-lo e significá-lo, brincando de ser adulto, ou seja, reinventando-o.

Outra característica a se destacar na ação infantil é seu caráter coletivo. A produção da criança dá-se pelas interações com os pares. Ela precisa do outro, ou seja, de colegas, irmãos, adultos para se ancorar e desenvolver suas atividades, principalmente quando essas envolvem o novo, o não-sabido. A ação da criança sobre os objetos e os outros indivíduos é sempre mediada pela interação, quer com adultos, quer com os pares.

Esse caráter coletivo da produção infantil também se expressará numa sociabilidade própria - os grupos de pares. A criança necessita do grupo para situar-se no mundo, estabelecendo uma relação diferenciada com os adultos, com códigos próprios. Esse universo grupal infantil não é desprovido de regras, mas, ao contrário, é carregado de normas, leis e punições que não reproduzem o universo social adulto, mas o ressignificam e reconstroem.

As crianças são ativas na sua própria construção da infância, nas formas institucionais sociais fornecidas pela sociedade infantil, aquelas formas inventadas e variáveis de organização e interação de parceiros, quer sejam os jogos que as crianças brincam, quer a sociedade das esquinas do bairro ou os até hoje misteriosos e inexplorados modos de transmissão cultural do saber e do humor infantil. (PERROTTI, 1982, p. 106)

Ou seja, existe não apenas uma especificidade da ação infantil na busca de compreensão do mundo, mas também sociabilidade e estratégias de aprendizagem diferenciadas, a serem melhor compreendidas. 
É com base nessa perspectiva e no diálogo com os referenciais teórico-metodológicos da sociologia da infância e da ciência antropológica que se buscou, neste trabalho, analisar como um grupo de crianças oriundas de famílias inseridas no Movimento dos Sem Terra MST - vive a condição da infância e compreende seu lugar social no diaa-dia de um acampamento em Minas Gerais.

Para tal, recorreu-se à observação participante do cotidiano infantil, por meio do acompanhamento de um grupo de sociabilidade constituído por crianças de idades variadas, organizadas em torno do brincar coletivo. $\mathrm{O}$ brincar aqui foi tomado como expressão da cultura infantil, atividade simbólica de ordenamento do real. A partir daí, foram realizadas, após seis meses de inserção no campo, entrevistas semidirigidas com um grupo de 12 crianças. Foram aqui destacados os depoimentos de três delas, com idades entre 7 e 12 anos.

A escolha dessas três crianças levou em conta o grau de inserção no "Movimento dos Sem Terrinha", que se verificou ser relacionado ao nível de participação dos pais no Movimento dos Sem Terra. Assim, destacamos duas crianças, filhos de militantes e participantes das atividades coordenadas pelo Movimento dos Sem Terrinha, e uma criança que não participava de tais atividades, à semelhança dos pais, que buscavam distanciar-se do MST, mesmo vivendo no acampamento.

Buscou-se analisar as diferentes visões das crianças sobre sua identidade social de participantes de um movimento coletivo que informava a experiência concreta da infância no cotidiano de um acampamento.

7 Denominação da organização dos adultos dirigida às crianças, no interior do MST, e que promove, sistematicamente, atividades voltadas para tal grupo geracional, tais como congressos, encontros, etc. 


\section{Vivências e aprendizados}

Compreendendo que, independentemente da idade, todos os sujeitos inseridos em qualquer fenômeno social podem ser importantes informantes que ajudam a compreender sua dinâmica, as crianças do MST foram buscadas para entender melhor a luta do Movimento. Não só porque são presença constante em todos os espaços criados e recriados no processo de luta pela terra, mas também para compreender como é vivenciar, dentro de um movimento social, as especificidades do período da infância, o processo de desenvolvimento, os espaços socializatórios, as múltiplas formas de se expressar e significar o mundo que tomam forma nas produções da cultura infantil (GOUVEA, 2003).

Por outro lado, voltar o olhar para o cotidiano dos movimentos sociais parece-nos algo importante para compreender a construção da identidade coletiva e de uma cultura de infância. E por que olhar para o MST como o lugar da vivência da infância? Em todo o Brasil, são mais de 160.000 crianças e adolescentes que estudam em escolas de acampamentos e assentamentos do MST. Como não levar em conta a construção da identidade de Sem Terra ${ }^{8}$ desde a infância, já que uma das características da sua luta é exatamente a presença de toda a família?

Um acampamento foi escolhido para realizar as observações por se acreditar ser esse espaço-tempo/vivência educativa a representação mais contundente da luta dos Sem Terra. As possibilidades trazidas por se estar acampado e de se tratar de um acampamento do MST são muitas: da ocupação do latifúndio à possibilidade de o acampamento sofrer uma ação de despejo ou à decisão de reocupar; das dificuldades financeiras sentidas de forma mais radical ao desafio de permanecer acampado e a

\footnotetext{
8 Este número não inclui as crianças que não estão em idade escolar e nem as que freqüentam escola no acampamento ou assentamento que ainda não são reconhecidas pelas redes públicas, como é o caso de muitas experiências de escolas itinerantes e das cirandas infantis. Fonte: $<$ www.mst.org.br/setores/educacao $>$.
} 
situação de instabilidade a que estão expostos; e até (muitas vezes) o (re)aprender a cultivar a terra.

A pesquisa de campo foi desenvolvida entre os meses de abril e novembro de 2003, na comunidade do Acampamento Alfa (nome fictício), em especial com crianças na faixa dos 7 a 12 anos de idade. A coleta de dados foi feita, principalmente, pela observação participante, com anotações em diário de campo e de entrevista com as crianças. Tratase de uma pesquisa de tipo etnográfico, que, segundo define André (2003), nas investigações em educação, contempla:

\begin{abstract}
A etnografia é um esquema de pesquisa desenvolvido pelos antropólogos para estudar a cultura e a sociedade. Etimologicamente, etnografia significa "descrição cultural" [...] Se o foco de interesse dos etnógrafos é a descrição da cultura (práticas, hábitos, crenças, valores, linguagens, significados) de um grupo social, a preocupação central dos estudiosos da educação é com o processo educativo.
\end{abstract}

(ANDRÉ, 2003, p. 27-28)

Concentramos aqui nossa análise no estudo do discurso de três crianças participantes do grupo (Cíntia, Emerson e Paula). Tal escolha teve como objetivo captar as diferentes construções de significado sobre a experiência de crescer num acampamento. Diferenças que se relacionam com o grau de pertencimento e participação dos pais no MST, fator que mostrou informar a inserção da criança no Movimento.

Enquanto Cíntia e Paula eram filhas de militantes e participantes das atividades promovidas pelo "Sem Terrinha", Emerson ocupava lugar mais distante, à semelhança de seus pais, pouco inseridos no Movimento. Assim é que a análise do grupo de pares buscou considerá-lo não como um grupo homogêneo, definido apenas pelo pertencimento geracional e pela inserção num movimento social significativo. Ao contrário, buscou- 
se conferir visibilidade à diversidade dos lugares sociais dos distintos membros do grupo. Ao tentar aprender a lógica diferenciada de inserção no grupo de pares, verificou-se o quanto as formas de sociabilidade infantis, aparentemente distintas das do grupo adulto, eram atravessadas pela sua lógica. Notadamente, a família constituía referência fundamental nas expressões e nos graus de participação infantil no movimento social. Tal aspecto revela a força que o grupo familiar exerce sobre os processos identitários da infância, definindo condições socializatórias diversas.

Por outro lado, essas crianças mostram uma experiência que constitui o fator central na conformação dos seus processos identitários: a luta pela terra. Quando, por exemplo, Cíntia disse: "Acho que não sou mais a mesma pessoa de antes" (e os outros dois depoimentos também deixam a mesma sensação), cabe refletir sobre o significado de tal discurso. Morar no acampamento Alfa aparece como um marco na vida dessas crianças.

Os discursos e práticas dessas crianças mostram não apenas a importância do pertencimento a um movimento social organizado na estruturação de sua identidade, mas também indicam o processo dessa construção. A luta vai se apresentando como uma vivência existencial total (ARROYO, 2000, p. 7), no sentido mais profundo que essa expressão possa apresentar: os sujeitos se encontram, o tempo inteiro, presentes (inclusive porque moram ali); trazem suas marcas identitárias, como geração, gênero ou etnia; participam de uma luta por condições elementaríssimas de vida (ARROYO, 2000, p. 7). O fazer-se/sentir-se/saber-se (FERREIRA, 2002) pertencente a um movimento social de luta pela terra aparece como um aprendizado que vai se consolidando, baseando-se na vivência pessoal em ações de luta social (CALDART, 2000, p. 106).

Trajetórias de vida bastante comuns entre essas crianças estão nos depoimentos: famílias pertencentes às classes populares, moradoras de bairros periféricos de uma região metropolitana muito marcada pelo 
êxodo rural e que resolveram juntar-se a um movimento social de luta pela terra. Segundo Stédile (2000), historicamente a luta pela terra carrega a característica de ser uma luta dos pobres. O pertencimento de classe é algo central neste processo, enquanto a origem rural não marcava a vivência dessas crianças, egressas de favelas de regiões metropolitanas. Tal fator constitui marca identitária perceptível a partir de aspectos de dois momentos significativos da trajetória de vida que as crianças evocavam: a experiência urbana inicial contraposta ao universo rural vivido posteriormente.

Quando Cíntia e Emerson nos contaram a vinda de suas famílias para o MST, apontavam um processo semelhante: os pais foram convidados por alguém do Movimento a participar da ocupação do Alfa. No caso de Paula, a relação do pai com o MST se deu por meio da inserção na militância: vendia livros, depois começou a participar de encontros e viagens com o Movimento e, por fim, estava entre os acampados. Posteriormente, tornou-se membro da direção do MST no estado de Minas Gerais. Em ambos os casos, parece que foi a partir da decisão do pai de participar da ocupação que toda a família foi trazida para o acampamento.

Talvez pelo fato de terem vindo da cidade, o tom de comparação entre os espaços rural e urbano foi algo recorrente. Não só porque o viver no campo parece ter proporcionado qualidade de vida melhor em muitos aspectos, mas por poderem contar com condições de que não usufruíam na cidade: nadar no rio, brincar na mata, cuidar dos bichos, desfrutar do espaço rural. Em suas falas, citavam problemas urbanos característicos, tais como poluição, roubos, violência no trânsito, tráfico de drogas, como elementos inerentes ao espaço da cidade. Em oposição, morar no acampamento era representado como a superação de tais questões. Apresentavam o Alfa como um lugar melhor: "Tem que aqui é melhor e lá [na cidade] é pior"; “a minha vida tá melhor aqui do que na cidade”. 
Nesse sentido, as condições e possibilidades de exploração do espaço constituem elemento extremamente significativo na vivência da infância. As crianças, ao analisar suas condições de moradia, centraram sua avaliação não no espaço doméstico, em que se opõe a precariedade do barraco de favela à ainda mais precária barraca de plástico. O espaço lúdico era destacado em suas falas, nas quais se contrapunham o limitado trânsito nas ruas e becos da favela e a amplidão do acampamento, possibilitador de uma ludicidade mais rica.

É interessante destacar a especificidade do olhar infantil sobre a vivência no acampamento. Se, para o olhar do pesquisador adulto, a experiência de viver numa barraca de plástico aparece associada à precariedade, para as crianças tal vivência significava a possibilidade do exercício cotidiano do brincar, em que o acampamento era representado como local idílico, sem as restrições do espaço urbano.

O brincar apareceu como atividade ordenadora da experiência social na narração da história de vida e nas práticas cotidianas infantis. $\mathrm{O}$ repertório de brincadeiras coletivas constituía expressão do lugar social de participantes de um acampamento. Assim é que, freqüentemente, as crianças brincavam de "assembléia", representando uma atividade cotidiana característica, bem como referiam-se a tais atividades a partir de seu lugar infantil. "Uma vez eu levantei a mão e eles contaram meu voto", falava Paula, orgulhosa do feito. Ao tematizar em suas brincadeiras a atividade das assembléias, ou delas tomarem parte, as crianças buscavam, na ação lúdica, compreender a lógica adulta, reproduzindo-a. Por outro lado, faziam-no interpretando a atividade adulta de acordo com a perspectiva infantil, em que destacavam não os temas e objetivos discutidos na assembléia, mas sua dimensão teatralizada. As crianças divertiam-se nas brincadeiras, repetindo o gestual adulto do levantar de braços, reproduzindo os processos de votação e contagem de votos. 
Nas brincadeiras com barro, repetidamente modelavam televisões grandes, às quais não tinham acesso, expressando o desejo de aquisição de um objeto de consumo (no acampamento, só era possível o uso de TVs pequenas, a bateria). As crianças em tal produção tematizavam e materializavam a singularidade de seu lugar social.

Nesse sentido, as brincadeiras afirmavam-se como estratégia de reprodução interpretativa da experiência social. Tal conceito, formulado por Corsaro (2002, p. 114), busca analisar como "as crianças apropriamse criativamente da informação do mundo adulto para produzir sua própria cultura de pares. Tal apropriação é criativa na medida em que tanto expande a cultura de pares (transforma a informação do mundo adulto de acordo com a preocupação do mundo de pares) quanto, simultaneamente, contribui para a reprodução da cultura adulta. Esse processo de apropriação criativa pode ser visto como uma reprodução interpretativa".

As crianças não apenas expressavam sua história nas brincadeiras, mas tinham como tema constante, nas narrativas, a singularidade de suas trajetórias de vida, conferindo a elas caráter épico. Sair da cidade e ir morar no campo, pelo que nos disseram Cíntia e Paula, foi um movimento complexo. Nem essas crianças nem suas famílias vieram para o Alfa logo depois da ocupação. A primeira família demorou 20 dias e a segunda, quase dois anos. Novas pessoas, vindas de lugares diferentes e com experiências diversas, novo espaço, novas formas de socialização exigiram demorado processo de adaptação.

A vivência da luta foi outro aspecto que destacaram em sua história: fosse na forma de enfrentamento direto (por ser um acampamento onde a posse da terra não está garantida por lei, como o assentamento), fosse por outras experiências que expressavam a afirmação da identidade de Sem Terra. Era essa situação permanente de conflito que definia as crianças como participantes de um movimento 
social, em que a vivência da infância dava-se por meio de experiências cotidianas coletivas de enfrentamento. Nas conversas, as crianças narraram reiteradamente o acontecimento central na história de participação no movimento: o embate em torno da ação de despejo. Pelo insistente recontar dos fatos, elaboravam a dramaticidade do vivido.

Uma ação de despejo é algo comum à maioria das ocupações de terra. Mas, para essas crianças, trata-se de uma vivência inédita. Em outubro de 2002, o acampamento recebeu uma ordem de despejo. Algumas imagens eram recorrentes na fala das crianças: a possibilidade do confronto direto com a polícia, as famílias que foram embora, o choro e o desespero de alguns, a sensação de dúvida ou insegurança e o medo de perder a casa e não ter para onde ir. Permanecer ali parece ter sido não apenas uma questão de enfrentamento direto com o Estado, ou com o proprietário da terra, mas também uma condição de acesso à moradia e ao trabalho, ou seja, de sobrevivência.

As crianças repetidamente demonstravam orgulho por não terem sido despejadas. Conquista a partir da qual foi forjada uma nova identidade coletiva de não apenas integrantes do MST, mas de participantes de um grupo vitorioso: “O Alfa não é igual aos outros. Tem acampamentos em que vem o mandado de despejo e os acampados e acampadas têm que sair". Segundo Emerson: "Foi a primeira vez que nós entrou aqui [...] teve despejo e nós não foi. Nós ficou aqui até hoje".

O que faz o Alfa diferente dos outros, no sentido de poder resistir a uma ordem judicial de despejo? Quando Paula afirmou que, depois de muito tempo de existência do acampamento, “[...] a polícia queria tirar nós daqui. Nós reagimos! Não deixamos! Não saímos daquil", o termo "nós" parece reafirmar a idéia de conquista coletiva, expressa numa forma muito própria de lutar do MST: ficar e resistir.

No discurso das crianças, elas faziam referência à tramitação jurídica do processo, com citação do nome dos juízes designados, 
indicativo do conhecimento da dimensão legal da luta e de seus trâmites. A experiência radical de participação num movimento social organizado fez com que a experiência infantil assumisse significados singulares, marcando um distanciamento da imagem da criança como habitante de um mundo social à parte. É importante destacar que a participação no movimento social adulto não retirou das crianças a condição infantil, conferiu-lhe, no entanto, significado diferenciado. Nas narrativas, as crianças demonstravam como projetavam uma identidade coletiva em que a experiência constituiu fator ordenador de uma visão de mundo. Mesmo considerando os lugares sociais diferenciados ocupados pelas distintas crianças, definidos pelo grau de inserção dos pais na experiência coletiva de resistência à ação de despejo, forjou-se uma identidade comum reiteradamente afirmada na linguagem.

Os três depoimentos também tematizaram outro aspecto característico do processo de adaptação em um acampamento. As crianças evocaram os amigos que se foram, crianças que saíram do acampamento devido a desistência das famílias de permanecer naquelas condições. Nem todos os que chegaram se mantiveram. Brigas eram apontadas pelas crianças como algo inerente à dinâmica do acampamento. Diante disso, citaram o conjunto de regras possibilitador da vivência coletiva: "Só não pode abusar [...] fazer coisas erradas aqui dentro, brigar, usar drogas aqui dentro, roubar [...]" (PAULA).

Mesmo aqueles que permaneceram nem sempre se mostraram totalmente adaptados ao novo modo de vida. A família de Emerson, mesmo vivendo no acampamento desde o início da ocupação, parece ter sempre procurado lugares mais distantes do restante da comunidade, em busca de privacidade. A criança justificava o fato de morar do outro lado da estrada "porque do outro lado tem sossego". Tal sossego, por outro lado, acarretava o fato de não haver crianças por perto, com as quais pudesse brincar. 
Outra situação em que viveram enfrentamento, dada a sua condição de Sem Terra, ocorreu na convivência cotidiana com os colegas na escola. A aceitação das crianças, pelos colegas e professores, foi uma conquista coletiva, em que foi necessária a presença dos pais para reivindicar melhor tratamento dispensado pela escola aos filhos. Se antes foram tratados como "bicho", "roubador de terra", foram progressivamente conseguindo o respeito dos colegas, chegando a formar novas amizades naquele espaço.

Quando falaram do processo de construção do respeito mútuo na escola, expressaram a importância da reafirmação da identidade na convivência com o outro (os demais colegas). Se a condição de participante do Movimento dos Sem Terra era positivada no interior do grupo, foi inicialmente estigmatizada na convivência com o outro: as demais crianças da escola. A superação do estigma exigiu das crianças um investimento na conquista de um espaço inicialmente hostil.

Isso não significou, para o grupo, uma opção por restringir-se ao espaço do acampamento. Ao contrário, quando questionadas se gostariam de estudar numa escola do Movimento, dentro do Alfa, responderam preferir continuar freqüentando a Escola Estadual. As crianças não queriam abrir mão da conquista de novas relações de sociabilidade, mesmo exigindo a superação do preconceito. Nesse sentido, como crianças, advogavam uma vivência que ultrapassasse os limites do espaço mais próximo, que lhes permitisse enriquecer suas experiências sociais, na convivência, nem sempre fácil e harmônica, com sujeitos inseridos em outros espaços sociais: demais alunos e professores da escola do município.

Outro espaço de sociabilidade e aprendizado a que fizeram referência foi sua participação no Programa de Erradicação do Trabalho Infantil - PETI -, citando-o como um lugar de brincar, de fazer artesanato, de freqüentar aulas de dança, natação, teatro, etc. Ao compararem os colegas do PETI com os colegas da escola, afirmavam que "lá os meninos 
gostam muito mais da gente". Tal fala revela como o pertencimento à mesma camada social possibilitou uma convivência menos conflituosa.

Nos depoimentos, as crianças citaram outros espaços próprios da luta do MST, propiciadores de uma experiência diferenciada da infância: encontros, assentamentos, visitas a outros acampamentos e marchas. Ao conhecerem um assentamento, estabeleceram comparação entre morar naquele espaço e morar no acampamento: cada família tinha seu pedaço de terra, plantações, escolas, casas de alvenaria, no lugar dos barracos de lona. Assim, opuseram a precariedade de sua(s) vivência(s) e a estabilidade desejada.

Outra vivência propiciada pela inserção no MST era a realização de viagens pelos filhos de militantes. Experiência à qual não teriam acesso fora do Movimento e que lhes permitia conhecer outros universos sociais. A construção da identidade daquelas crianças inscrevia-as num lugar social singular: de um lado, eram excluídas de uma série de benefícios, de outro, tinham vivências que seriam inacessíveis a sujeitos de sua classe social.

O aprendizado do trabalho com a terra era algo destacado pelas crianças em seu discurso. Nos três depoimentos, isso surgiu como outra vantagem de se morar no acampamento. Cíntia falava, por exemplo, que, depois de ter ido morar no acampamento, teve outros aprendizados porque, "antes, na cidade, você não sabia nada direito [...], você não sabia plantar um milho, agora eu já sei isso". Foi Emerson quem falou, com mais paixão, não só da relação com a terra, mas principalmente com o trabalho no campo: explicava os processos de plantio do milho, do cuidado com os animais. O que Emerson tematizou em sua fala indica que o trabalho no campo constituiu aprendizado não somente para as crianças, mas também para os adultos, egressos do mundo urbano. Assim é que o deslocamento do espaço urbano para o rural significou não apenas a radical transformação do cotidiano das crianças e de suas famílias, mas também a aquisição de novos conhecimentos, definidos pelo trabalho com a terra. 
As três crianças revelaram ter em comum uma expectativa de futuro: "Eu espero que a terra aqui sai e que todos aqui, e minha família principalmente, seja muito feliz (Cíntia)"; "Tem que ficar lutando pra ver se a terra sai. [...] Se não sair? Uai! Ocupação [de] outra terra. Fazer o quê? (Emerson)"; "Um dia esta terra ser assentada, ter muitas plantações, as casas de tijolo (Paula)". Para as crianças, estar acampado constituía apenas uma fase de transição, uma vez que o assentamento era o lugar definido pela estabilidade: plantações, casas de tijolo, um lugar onde poderiam ser felizes definitivamente, conferindo um caráter "épico" à própria história. $\mathrm{Na}$ impossibilidade dessa conquista, não manifestavam dúvida do que fazer: ocupar outra terra.

Depreende-se dos depoimentos dessas crianças a singularidade da experiência da infância no interior de um movimento social. Por um lado, referiam-se a vivências próprias da condição infantil e do lugar social da criança na cena contemporânea: a centralidade do brincar, a importância dos grupos de sociabilidade, a inserção na escola. Por outro, a identidade geracional era plasmada à identidade de participante de um movimento coletivo: a vivência em um acampamento, as experiências de enfrentamento e conflito, o estigma da identidade de Sem Terra na escola, a participação no Movimento das crianças Sem Terra, propiciadora de vivências às quais não teriam acesso, dada sua condição social.

É com base nessas referências identitárias - geração e inserção social - que as crianças produziram uma identidade singular. A pesquisa indica que, no estudo da infância, cabe investigar as múltiplas experiências concretas das crianças, a vivência da condição infantil. É importante considerar as diferenciações internas à categoria infância e contemplar o cruzamento com outras categorias de análise: pertencimento étnico, social e cultural, que informam o processo de construção de diferentes infâncias e de socialização da criança. 
Tal perspectiva permite-nos superar as generalizações e a construção de padrões normativos universais e abstratos que caracterizaram os estudos tradicionais sobre a criança, no campo da Psicologia e da Pedagogia. É por meio de um enfoque interdisciplinar que se torna possível a construção de saberes sobre o significado do pertencimento geracional da criança na cena contemporânea, considerando-a como ator social, produtora e produto de uma cultura diferenciada.

\section{Algumas reflexões a respeito do processo}

\section{da coleta de dados da pesquisa}

Em vários momentos, no decorrer do processo da coleta de dados, um sentimento de desconforto, de insegurança por parte das crianças foi detectado. Ao serem abordadas, por exemplo, para iniciar uma "conversa" (que seria a entrevista), elas iam indagando à pesquisadora "se as perguntas seriam difíceis", "se não seria melhor fazer a entrevista às mães delas".

Chamou-nos a atenção a expressão, por parte das crianças, de um sentimento de incapacidade de emitir opinião, ainda que o assunto fosse a sua própria vida. Em certa medida, algo foi-se tornando um desafio da pesquisa: convencer as crianças de que as brincadeiras, a fala, as expressões próprias eram importantes fontes de pesquisa.

Nossa opção metodológica, ao priorizarmos a fala das crianças e a escuta por parte do pesquisador, justifica-se pela crença na importância da construção de uma relação entre pesquisador e grupo pesquisado. Relação essa marcada pela convicção de que conceber os seres humanos como sujeitos pressupõe abrir espaço para eles se expressarem.

No caso específico desta pesquisa, as crianças foram consideradas como detentoras de sinais a respeito de sua condição de Sem Terra. Uma experiência de vida marcada pela busca de superação da condição de exclusão social, processo que se manifesta em diferentes situações. A própria 
participação na pesquisa, ao relatarem sobre o seu cotidiano no acampamento, na escola, no PETI, junto às suas famílias, nos diferentes momentos de brincadeira, foi uma oportunidade de expressão vivenciada pelas crianças e reforça a importância de se sentirem reconhecidas pelo outro.

O clima de confiança foi sendo criado e, com ele, a espontaneidade infantil foi ganhando espaço. Uma vez mais se confirma a importância das interações face a face, do cultivo dos vínculos afetivos entre pesquisadores e pesquisados, educadores e educandos.

O próprio processo da pesquisa configura-se como uma experiência propiciadora de superação da condição de exclusão social. $\mathrm{O}$ sentir-se incapaz de responder às perguntas, de expressar sua opinião, refletir a respeito da própria vida, vai sendo pouco a pouco superado.

A convivência cotidiana com a pesquisadora foi ganhando os contornos de uma relação educativa à medida que se propiciou às crianças dizerem a si mesmas, "no contexto concreto de seu tempo e de seu espaço e no contato com outras pessoas, grupos e categorias de pessoas que estejam vivenciando o mesmo processo" (AMATUZZI, 1986, p. 15).

Se os sujeitos em geral, como nos alerta Amatuzzi, cresceram ensinados a não se dizerem a si mesmos, mas a se deixarem dizer, essa realidade se agrava ainda mais nas camadas populares.

Ao se sentirem reconhecidas pelo outro (aqui, no caso, pela pesquisadora), as crianças foram ganhando espaço de expressão, emergindo na possibilidade do auto-reconhecimento, refazendo a autoimagem negativa (incapaz de se expressar, de emitir opinião...).

A introjeção da inferioridade naturalizada passa a ser tocada de maneira profunda, começando a desinstalar aquela "construção" quase cristalizada. A relação construída entre a pesquisadora e as crianças do acampamento Alfa do MST alerta para a riqueza da dimensão relacional da educação. Por meio dela, foi reforçada a crença no ser humano como participante de um processo constante de mudança. A introjeção da 
inferioridade vivenciada pelos sujeitos das camadas populares é, sem sombra de dúvida, um difícultador no processo de superação da desigualdade social. Não se trata, porém, de algo intransponível. Pelo contrário, assim como foi fruto de um processo vivenciado nas "relações humanas", essa mesma porta - a das relações - oferece possibilidades de construção do seu contrário. Enfim, entre as várias aprendizagens propiciadas por esta pesquisa, esta se manifestou de forma muito evidente.

É importante considerar, ao analisar as crianças como atores sociais, que, mesmo tendo instâncias próprias de participação no movimento coletivo, o Movimento dos Sem Terrinha, isso não garantia que elas encontrassem canais de expressão de reivindicações específicas. No caso da escolha do modelo de escolarização, a tensão entre o grupo geracional adulto e o infantil manifestava-se de forma mais clara. Enquanto a opção do movimento era a construção de escolas específicas para suas famílias, as crianças preferiam expandir seus espaços e pares, no exercício da sociabilidade infantil, e freqüentar a escola regular. Mesmo diante do estigma vivido no enfrentamento do outro (crianças com experiências distintas), o enriquecimento do universo social aparecia como o fator mais importante na definição de um projeto escolar.

\section{REFERÊNCIAS}

AMATUZZI, Mauro M. O resgate da fala autêntica. Campinas: Papirus, 1986.

ANDRE, M. E. D. A. Etnografia da prática escolar. 2. ed. revisada. Campinas: Papirus, 2003.

ARROYO, M. G. Pedagogias em movimento - o que temos a aprender dos movimentos sociais? Belo Horizonte, 2000. (Mimeogr.)

CALDART, R. S. Pedagogia do Movimento Sem Terra - escola é mais que escola. 2. ed. Petrópolis: Vozes, 2000. 
CORSARO, William. A reprodução interpretativa. In: Educaşão, sociedades e culturas. Crescer e aparecer...ou para uma sociologia da infância. Porto, n. 17, p. 97-135, 2002.

FERREIRA, M. Do "avesso" do brincar ou... as relações entre pares, as rotinas da cultura infantil e a construção da(s) ordem(ens) social(ais) instituintes das crianças no jardim-de-infância. In: SARMENTO, M.; CERISARA, A. B. (Orgs.). Crianças e miúdos: perspectivas sociopedagógicas da infância e da educação. Porto: Edições Asa, 2002. p. 55-104.

GOUVEA, Maria Cristina. Infância, sociedade e cultura. In: SALES, Fátima; GUIMARAES, Marilia (Orgs.) Desenvolvimento e aprendizagem. Belo Horizonte: UFMG, 2003. p. 7-25.

GOUVEA, Maria Cristina. Processos de significação do mundo pela criança. In: PAIVA, Aparecida (Org.) O jogo do livro infantil. Belo Horizonte: Autêntica, 2006 (no prelo)

MACEDO, G. O lugar do significado no processo de alfabetização: um estudo da cartilha "Pipoca" e do Manual de Instrução do Professor. 1993. Dissertação (Mestrado em Educação) Faculdade de Educação, Universidade Federal do Rio Grande do Norte, Natal, 1993.

MST. Construindo o Caminho Numa Escola de Acampamento do MST. 2000. (Coleção Fazendo escola)

PERROTI, Edmir. A criança e a produção cultural. In: ZILBERMAN, R. (Org.). A produção cultural para a criança. Porto Alegre: Mercado Aberto, 1982. p. 101-117.

PINTO, Manuel. A infância como construção social. In: SARMETO, M.; PINTO, M. (Orgs.) As crianças, contextos e identidades. Braga: Instituto de Estudos da Criança- Universidade do Minho, 1998. p. 45-67.

QUINTEIRO, Jucimara. Infância e educação no Brasil: um campo em construção. In: FARIA, Ana Lúcia; DEMARTINI, Zélia; PRADO, Patrícia (Orgs.) Por uma cultura da infância. Campinas. Autores Associados, 2002. p. 19-48. SARMENTO, Manuel. As culturas da infância nas encruzilhadas da segunda 
modernidade. In: SARMENTO; CERISARA (Orgs.) Crianças e miúdos. Porto: Asa, 2004. p. 9-35.

SARMENTO, Manuel. Gerações e alteridade: interrogações a partir da sociologia da infância. In: Dossiê Sociologia da Infância: pesquias com crianças. Educação e Sociedade, v. 26, p. 361-378, maio/ago. 2005.

SOUZA, Solange Jobim. Infância, conhecimento e contemporaneidade. In: KRAMER, Sônia; LEITE, Maria Isabel. (Orgs.). Infância e produção cultural. Campinas: Papirus, 1997. p. 8-25.

STÉDILE, J. P. Latifúndio: o pecado agrário do capital. São Paulo: MST, 2000.

Recebimento: 06/03/2005

Aprovação: 31/07/2006

\section{Contato:}

Faculdade de Educação - Fae/UFMG

Av. Antonio Carlos, 6627 - Pampulha

Cep: 31270-910.

Belo Horizonte/MG.

E-mail: crisoares@yahoo.com.br 